\title{
Pesticide alters oviposition site selection in gray treefrogs
}

\author{
James R. Vonesh · Julia C. Buck
}

Published online: 14 October 2008

(C) Springer-Verlag 2008

Erratum to: Oecologia (2007) 154:219-226

DOI 10.1007/s00442-007-0811-2

The third to last sentence of the 'Methods' subsection entitled 'Experiment 4: Isolating the chemical mechanism' should read: 'No aquatic trophic structure was established and colonists were removed every 3-6 days $(\text { mean }=4.3)^{\prime}$ '. The last sentence of this paragraph should read: 'The experiment ran from 30 June to 17 July 2006'.

The online version of the original article can be found under doi:10.1007/s00442-007-0811-2.

J. R. Vonesh · J. C. Buck

Tyson Research Center, Washington University in Saint Louis,

One Brookings Drive, Campus Box 1229,

St. Louis, MO 63130-4899, USA

J. R. Vonesh $(\square)$

Department of Biology, Virginia Commonwealth Univesity,

1000 West Cary Street, P.O. Box 842012,

Richmond, VA 23284-2012, USA

e-mail: jrvonesh@vcu.edu 